\title{
Evaluation on Ecological City assessment mechanism construction based on gray correlation theory
}

\author{
Xiangjun $\mathrm{Pu}$ \\ School of Urban Design, Wuhan University, Wuhan, Hubei, China \\ Corresponding E-Mail:Xiangjunpuer@126.com
}

Keywords: Ecological civilization ;Culture of mining and metallurgy

\begin{abstract}
The construction of ecological civilization of the city is related to public welfare, while the culture of mining and metallurgy is the typical characteristics of a typical resource-based city. This paper takes the culture of mining and metallurgy as the breakthrough point, based on analyzing the value of the culture of mining and metallurgy on the modernization of the city, discussing how to construct the evaluation index system of ecological civilization city, method, as well as the evaluation system.
\end{abstract}

\section{Introduction}

City is the symbol of human civilization, which is also the reduction of the social development, it is not only economic center for a country or a region, but also is the focus and the birthplace of culture. Some scholars even think that "the culture is the city". Because city itself is the product of human civilization and progress, which is the crystallization of the culture. With the process of city's development, change and disappearance, it can not do without culture for a while. Especially, the development of human civilization has developed into a new stage, the important status and role of culture that it played in the city's innovation and development is increasingly prominent.

\section{The Overview of the Culture of Mining and Metallurgy}

The culture of mining and metallurgy is the idea and behavior criterion of human who are engaged in mining activities in the form of human mining activities, which essence is group cooperation, pioneering spirit, the humanistic spirit of inclusiveness, mandatory norms.

The characteristics of the culture of mining and metallurgy can be include as follows: first of all , inheritance. Mining and smelting can not do without technology, and the development of technology is a process of inheritance with innovation, this process can reflect the culture of mining and metallurgy, which is the characteristics of technical inheritance. Secondly, expansibility. The culture of mining and metallurgy is a kind of cultural industry, and the characteristics of industry is multi-directional extension, which can form the industrial chain, this feature reflects the culture of mining and metallurgy, constituting the culture of mining and metallurgy development characteristics. Thirdly, cross pollination. The culture of mining and metallurgy can be blended with other kinds of culture, developing a new development point.

\section{The Value of Culture of Mining and Metallurgy on the City 's Modernization}

The culture of city is a microcosm of social harmony, which can represent the social civilization, social harmony as well as city's civilization, it is the concentrated expression of the city in some degree. Today is an era of knowledge economy, today people live in an information era, the transformation of economic growth from the extensive type to the intensive type, which is more depended on knowledge and information. While "the cultural productive forces" is a word, which is emerged as the times required, we must focus on the role of culture in the economic development as the productive forces. From the inner world of culture, it can play an effective influence on people, which can be called as appealing power, cohesion that is often said by people. It is through the 
ideals and beliefs, values, the spirit of innovation and dedication that can guide, regulate, stimulate and promote human behaviors, so as to underpin interpersonal relationship and increase people's subjective initiative, ultimately enhance the vitality of the city.

\section{The Interpretation of Evaluation Index System of City's Ecological Civilization}

With the development of the city, the contradiction between the city residents and the resources and environment will continue to increase, therefore, we should solve the contradictions and problems between the economic development and environment fundamentally, China must implement the comprehensive construction of ecological civilization, especially in the construction of city's ecological civilization. The evaluation index system of city's ecological civilization is a basic problem related to the theory of city's ecological civilization, the theory of city's construction is to describe the theory of management, the theory of city planning and city integrated as well as many other theories in the construction of ecological civilization. During the development of the city, we need to have a scientific and reasonable evaluation index system of the city's ecological civilization construction.

\section{Selecting Principles of City's Evaluation Index of Ecological Civilization Construction}

The principle of combining commonness and characteristics. During the selection of the domestic and foreign universal and practical significance of the index, at the same time, it should highlight the characteristics of the economically developed cities, forming the type of evaluation with regional characteristics.

The principle of combining the development of inheritance and innovation. Retaining the traditional national ministries and other of "scientific development view" of the provinces, "ecological city" as well as the index system of the essence of indicators, so as to improve the related indicators and standards .

\section{Basic principles of grey correlation degree}

Gray correlation method is proposed by deng julong, it can make quantitative analysis to the system dynamic change with the situation, to investigate the correlation degree between the system factors. Gray correlation method is on the basis of system series of geometric shapes, curve graph similarity between research variables.Using the gray relation method, we can compare performance of a single food enterprise in different periods using vertical evaluation; also can compare between different companies in the same industry's financial status using transverse evaluation; The indicators can be stratified analysis

According to the gray correlation analysis of the gray system theory, the size of the gray correlation reflects the reference sequence and comparative sequence similarity. According to the different features between the gray value of the index layer points and the gray value of the background area is large, it is understood that the layer and its neighboring pixel values consisting of comparison sequence associated with the reference sequence is relatively small. The calculating process of Grey absolute correlation degree are described as follows.

The calculation steps of correlation degree is as follows.

Let the reference sequence $X_{0}:\left\{x_{i}(k), k=1,2, \cdots, n\right.$,

comparison sequence $X_{i}:\left\{x_{i}(k), k=1,2, \cdots, n\right.$.

( 1 ) initialization:

$$
Y_{0}:\left\{\frac{x_{0}(k)}{x_{0}(1)}=y_{0}(k) \quad Y_{1}:\left\{\frac{x_{i}(k)}{x_{i}(1)}=y_{i}(k)\right.\right.
$$

Initialized so that all sequences comparable.

( 2 ) calculate the correlation coefficients of each point : 


$$
\begin{gathered}
r\left(y_{0}(k), y_{i}(k)\right)=\frac{1}{1+\left|\left(y_{0}(k+1)-y_{0}(k)-y_{i}(k+1)-y_{i}(k)\right)\right|} \\
k=1,2, \cdots, n-1
\end{gathered}
$$

(3) calculate the correlation degree:

$$
r\left(x_{0}, x_{i}\right)=\frac{1}{n-1} \sum_{k-1}^{n-1} r\left(y_{0}(k), y_{i}(k)\right)
$$

Its basic algorithm thought: put index in the each pixel points corresponding to gray value considered initial series of Grey forecast model, then, put index in the pixel points $x$ and its neighborhood pixel points into original sequence, accumulate the original sequence by using data processing for a regular series of Grey modeling, again for Grey forecast, after getting the forecast value sequence, for data reduction by that point in the actual forecast data ,if the difference between forecast value and actual value is larger, which is for layer points, otherwise, for non-layer points. The main steps of the algorithm of GM $(1,1)$ model are shown as follows:

(1) let the original sequence as

$$
x^{(0)}=\left(x_{(1)}^{(0)}, x_{(2)}^{(0)}, \cdots, x_{(n)}^{(0)}\right)
$$

(2) generates a sequence for the record

$$
x^{(1)}=\left(x_{(1)}^{(1)}, x_{(2)}^{(1)}, \cdots, x_{(n)}^{(1)}\right)
$$

Among them , $\quad x_{(k)}^{(1)}=\sum_{i=1}^{k} x_{(i)}^{(1)} \quad k=1,2, \cdots, n$.

(3) $z^{(1)}$ is close to $x^{(1)}$ as the mean value generates a sequence

Among them, $\quad z_{(k)}^{(1)}=0.5 x_{(x)}^{(1)}+0.5 x_{(k-1)}^{(1)}, \cdots, k=2,3, \cdots, n$

$$
z^{(1)}=\left(z_{(2)}^{(1)}, z_{(3)}^{(1)}, \cdots, x_{(n)}^{(1)}\right)
$$

(4) GM $(1,1)$ model that is an order of one yuan gray model, which is defined as

$$
x_{(k)}^{(0)}+a z_{(k)}^{(1)}=b
$$

where: $\mathrm{a}$ is a factor of development; $\mathrm{b}$ is the Grey action.

(5) The whiting model of $\operatorname{GM}(1,1)$ is

$$
\frac{d x^{(1)}}{d t}+a x^{(1)}=b
$$

(6) The albino-response of GM $(1,1)$ is

$$
\begin{aligned}
& \wedge_{(k+1)}^{(1)}=\left(x_{(1)}^{(0)}-\frac{b}{a}\right) e^{-a k}+\frac{b}{a} \\
& \wedge(0) \\
& x_{(k+1)}=x_{(k+1)}^{(1)}-x_{(k)}^{(1)}
\end{aligned}
$$

(7) under the least-squares criterion parameter

$$
\left[\begin{array}{l}
a \\
b
\end{array}\right]=\left(B^{T} B\right)^{-1} B^{T} y^{n}
$$

Among them ,

$$
B=\left[\begin{array}{cc}
-z_{(2)}^{(1)} & 1 \\
-z_{(3)}^{(1)} & 1 \\
\vdots & \vdots \\
-z_{(n)}^{(1)} & 1
\end{array}\right] \quad y^{n}=\left[\begin{array}{c}
x_{(2)}^{(0)} \\
x_{(3)}^{(0)} \\
\vdots \\
x_{(n)}^{(0)}
\end{array}\right]
$$

The strong layer detection based on Grey prediction of Grey forecasting model of index layer detection studies focus on the sequence of points on the options, and options for sequence points improvements are only detects the layers more informative, does not meet the requirements of full 
index layer. Based on Grey forecast detection out of layer exists serious of fracture phenomenon, but its can accurate to find index layer of location, this paper has a new idea, puts Grey forecast application into index index of strong layer of detection, base on strength layer connection of thought, and put this strong layer and by Niblack value of the two algorithm get of weak layer for connection, then get index of layer information.

Based on the Grey prediction model in sequence point selection scheme and index index Gray scale characteristics analysis, the paper selected 12 masked sequences, and choose GM(1,1) model to model, thus get the strong layer in the index. The specific Grey prediction algorithm of the main steps are described below.

Let the size of an $\mathrm{M} \times \mathrm{N}$ index I, the Grey value of midpoint $I(i, j)$ is $g(i, j), \quad i=1,2, \cdots, M$,

$$
J=1,2, \cdots, N
$$

(1)for each pixel in the index I, in turn, use mas sequences and $G M(1,1)$ model to calculate the gray forecast value of the center point $\mathrm{x}$ and constitutes the forecast index II.

(2) Original I minus the predicted figure II gets error indexs III, its gray value of each point is $\xi(i, j)$.

( 3 ) According to the error histogram of the index, the threshold value T, if $\xi(i, j)>T$, the pixel index $B(i, j)=1$ is the binary index of strong layers, otherwise, $B(i, j)=0$, thus, getting the binary indexs of layers obtained by gray forecast model .

According to the gray correlation analysis of the gray system theory, the size of the gray correlation reflects the reference sequence and comparative sequence similarity. According to the different features between the gray value of the image edge points and the gray value of the background area is large , it is understood that the edge and its neighboring pixel values consisting of comparison sequence associated with the reference sequence is relatively small. The calculating process of Grey absolute correlation degree are described as follows.

The calculation steps of correlation degree is as follows.

Let the reference sequence $X_{0}:\left\{x_{i}(k), k=1,2, \cdots, n\right.$,

comparison sequence $X_{i}:\left\{x_{i}(k), k=1,2, \cdots, n\right.$.

( 1 ) initialization:

$$
Y_{0}:\left\{\frac{x_{0}(k)}{x_{0}(1)}=y_{0}(k) \quad Y_{1}:\left\{\frac{x_{i}(k)}{x_{i}(1)}=y_{i}(k)\right.\right.
$$

Initialized so that all sequences comparable.

( 2 ) calculate the correlation coefficients of each point :

$$
\begin{gathered}
r\left(y_{0}(k), y_{i}(k)\right)=\frac{1}{1+\left|\left(y_{0}(k+1)-y_{0}(k)-y_{i}(k+1)-y_{i}(k)\right)\right|} \\
k=1,2, \cdots, n-1
\end{gathered}
$$

(3) calculate the correlation degree:

$$
r\left(x_{0}, x_{i}\right)=\frac{1}{n-1} \sum_{k-1}^{n-1} r\left(y_{0}(k), y_{i}(k)\right)
$$

In this paper, it can use the normalization method of index dimensionless processing. Taking the original value $X_{i}$ of the $i$ index as the high level of $M_{i}$, the low value is $m_{i}$, then after normalizing, the index is $R_{i}$, the normalizing formula for different index is:

The index of efficiency:

The index of cost:

$$
R_{i}\left\{\begin{array}{cc}
1, & x_{i} \geq M_{i} \\
\frac{x_{i}-m_{i}}{M_{i}-m_{i}}, & m_{i}<x_{i}<M_{i} \\
0, & x_{i} \leq m_{i}
\end{array}\right.
$$




$$
R_{i}\left\{\begin{array}{cc}
1, & x_{i} \leq m_{i} \\
\frac{M_{i}-x_{i}}{M_{i}-m_{i}}, & m_{i}<x_{i}<M_{i} \\
0, & x_{i} \geq M_{i}
\end{array}\right.
$$

Using the principle of AHP method, then the index is constructed by the judgment matrix, by using this method it can determine the weight of index, the judgment matrix can be denoted as:

$$
A=\left[\begin{array}{cccc}
C_{11} & C_{12} & \cdots & C_{1 n} \\
C_{21} & C_{22} & \cdots & C_{2 n} \\
\vdots & \vdots & & \vdots \\
C_{n 1} & C_{n 2} & \cdots & C_{n n}
\end{array}\right]
$$

Among them, $C_{i j}$ can represent the ratio of the importance of the $i$ index to the $j$ index during evaluating the evaluation target, generally speaking, it can use the scale from 1 to 9 to represent the value of $C_{i j}$, the value of $C_{i j}$ is from $1 / 9$ to 9 , which can represent the importance of $i$ index during evaluating the item. The importance of $i$ index to the $j$ index can be from the extreme non-importance to the extreme importance, and through the relative weight of each index by the maximum eigenvector eigenvalue to get the corresponding judgment matrix.

\section{Conclusion}

Research on the evaluation method of the construction of city's ecological civilization is a major requirement during the process of China's ecological civilization construction, which is also one of the hot researches in the academic circles at present. This research can provide technical evaluation on the ecological civilization construction for the developed city, but also can provide reference for the other types of index system of ecological civilization in China.

\section{Reference}

[1]Antonio M. Bento, Maureen L. Cropper. The effects of urban spatial structure on travel demand in the United States. Review of Economics and Statistics, (2005). vol.87, pp:466-478.

[2]Bhargav Adhvaryu. Analysing evolution of urban spatial structure: a case study of Ahmedabad, India. Environment and Planning-Part B, (2011).vol.38, pp850.

[3]Sako Musterd, Wim Ostendorf. Urban segregation and the welfare state: Inequality and exclusion in western cities. Routledge. (2013 ).pp:34-38.

[4]Daniel T. Lichter, David L. Brown. Rural America in an urban society: Changing spatial and social boundaries. Annual Review of Sociology. (2011).Vol.77, pp565-592. 